\title{
Impact of pneumococcal conjugate vaccine on the prevention of invasive pneumococcal diseases
}

\author{
Lucia Ferro Bricks, ${ }^{1}$ Eitan Berezin ${ }^{2}$
}

\begin{abstract}
Objectives: To evaluate the impact of heptavalent pneumococcal conjugate vaccine in invasive pneumococcal diseases in the United States, and to analyze the potential impact of this vaccine in Brazil.

Sources of data: MEDLINE, LILACS, Cochrane Database Reviews, as well as the websites of the Centers for Disease Control and Prevention (CDC), Brazilian Ministry of Health and Centro de Vigilância do Estado de São Paulo, from January 2000 to January 2006. Articles retrieved with the keywords Streptococcus pneumoniae, pneumococcal diseases, conjugate vaccine, antimicrobial resistance and meningitis were reviewed.

Summary of the findings: The introduction of heptavalent pneumococcal conjugate vaccine caused a dramatic reduction in the incidence of invasive pneumococcal diseases in American children, reduced antibiotic use and the number of medical visits due to otitis media and pneumonia by children. The incidence of invasive pneumococcal diseases caused by resistant strains declined in immunized children, adults and elderly individuals. In Brazil, the mortality rate of pneumococcal meningitis is very high and the resistance to antibiotics has increased over the last 5 years.

Conclusions: Heptavalent pneumococcal conjugate vaccine can benefit not only children, but the entire community and should be included in the Brazilian routine immunization schedule.
\end{abstract}

J Pediatr (Rio J). 2006;82(3 Suppl):S67-74: Streptococcus pneumoniae, pneumococcal disease, conjugate vaccines, pneumonia, meningitis, antimicrobial resistance.

\section{Introduction}

Streptococcus pneumoniae (pneumococcus) is the main etiologic agent of pneumonias and invasive diseases in children and adults (Table 1). It is estimated that in developing countries, pneumococcus is responsible for over 1 million deaths per year in children younger than 5 years, the majority in developing countries. ${ }^{1-3}$ In spite of pneumonias causing the largest number of deaths, the mucosal diseases caused by pneumococcus are more common, and the use of antibiotics to treat otitis and sinusitis have been associated with the appearance and dissemination of antibiotic resistant strains. ${ }^{4-7}$

Pneumococcal diseases are more common in children younger than 2 years, elderly people, and in certain groups of individuals that present conditions associated with the development of invasive pneumococcal diseases (IPD) (Table 2).1-12 Moreover, they affect poorer

1. Professora Doutora, Departamento de Pediatria, Faculdade de Medicina da Universidade de São Paulo (FMUSP), São Paulo, SP, Brasil. Médica assistente, Instituto da Criança, Hospital das Clínicas da Faculdade de Medicina da Universidade de São Paulo, São Paulo, SP, Brasil.

2. Professor adjunto, Departamento de Pediatria, Faculdade de Ciências Médicas da Santa Casa de São Paulo (FCMSCSP), São Paulo, SP, Brasil. Chefe, Serviço de Infectologia Pediátrica, Santa Casa de São Paulo, São Paulo, SP, Brasil.

Suggested citation: Bricks LF, Berezin E. Impact of pneumococcal conjugate vaccine on the prevention of invasive pneumococcal diseases. J Pediatr (Rio J). 2006;82(3 Suppl):S67-74. populations more seriously, aggravating the situation of these populations even further. ${ }^{1,4}$

In Brazil, the highest rate of incidence of pneumococcal meningitis has been registered in nursing infants younger than 1 year, and bacterial resistance has increased progressively.6,7,11 From 1983 to 2003, the number of cases of meningitis from pneumococcus was 29,600 , with 8,554 deaths.

It is estimated that pneumococcus is the main pneumonia agent in almost all age groups. In Brazil, in 2004, the frequency of hospitalization due to pneumonias in children $<5$ years was $2,500 / 100,000$, and the mortality rate from respiratory disease reached $25 / 100,000$ in this age group. ${ }^{11}$ The number of cases of pneumonia acquired in the community and confirmed by radiological exam in children $<5$ years is substantially higher $(566 / 100,000)$, particularly among children who live in precarious conditions. $^{4}$

The importance of pneumococcal diseases and the increase in bacterial resistance have made it essential to develop vaccines to prevent these diseases, since the 23valent polysaccharide vaccine (PN23), licensed in 1983, is recommended only for people over 2 years of age. ${ }^{1}$

The success of conjugate Haemophilus influenzae type $b(\mathrm{Hib})$ vaccines in several countries encouraged the development of new conjugate vaccines against 
Table 1 - Diseases caused by pneumococcus

\begin{tabular}{lc}
\hline Non-invasive diseases & Invasive diseases* \\
\hline Acute otitis media & Bacteremia \\
Sinusitis & Bacteremic pneumonia / empyema \\
Conjunctivitis & Meningitis \\
Bronchitis & Sepsis \\
Pneumonia & Peritonitis \\
& Arthritis / osteomyelitis \\
\hline
\end{tabular}

* Invasive diseases: isolation of pneumococcus from usually sterile sites (blood, cephalorachidian, pleural or sinovial liquid).

Table 2 - Risk groups for invasive diseases caused by $S$. pneumoniae

- Children < 5 years of age;

- The elderly (> 65 years);

- People with compromised immune response because of congenital or acquired disease (including symptomatic and asymptomatic HIV patients) or those who are undergoing immunosuppressor treatments;

- People with anatomic of functional asplenia (includes hemolytic anemias, such as sickle cell anemia and others);

- Patients with chronic diseases (nephropathies, cardiorespiratory diseases, diabetes, alcoholism, cirrhosis, asthma, deposit diseases and trisomies);

- Individuals with cranial fracture, liquorice fistula and those submitted to cranial surgery, including cochlear implant placement;

- Some ethnic groups (Navajo and Apache Indians, natives of Alaska and Australia, blacks);

- People who live in crowded environments (day care centers, schools) or who are in contact with children;

- People exposed to cigarette smoke;

- After viral infections, particularly post-influenza and infection by respiratory syncytial virus.

pneumococcus, and in 2000, the first conjugate $S$. pneumoniae vaccine was licensed. ${ }^{12}$ In this article, we present the data published over the last 5 years about the impact of the use of the conjugate 7-valent (Pnc7) vaccine with regard to pneumococcal diseases and bacterial resistance.

\section{Conjugate 7-valent S. pneumoniae (Pnc7) vaccine}

The Pnc7 (Prevenar ${ }^{\circledR}$ ) vaccine is produced by the Wyeth ${ }^{\circledR}$ laboratory and contains serotypes 4, 6B, 9V, 14, 18C, 19F, 23F conjugated to a diphtheria toxin mutant the protein CRM197. Of the over 90 S. pneumoniae serotypes, the seven included in the Pnc7 vaccine were responsible for approximately $85 \%$ of the IPDs in American children before it was introduced in the USA's basic vaccination calendar. ${ }^{1,12,13}$

Pnc7 vaccine was licensed after publication of the Kaiser Permanent Study Center results, a controlled study that included 37,868 children from northern California, revealing that the Pnc7 vaccine efficiency was $97.4 \%$ against the IPDs caused by the vaccine serotypes (VST). Only one of the 40 IPD cases was in the group that completed the vaccination scheme; in the group that received one or more doses of the vaccine, there was also high protection (93.9\%). The vaccinated children had a larger number of medical visits for otitis ( $8.9 \%)$, a lower number of otitis episodes $(7 \%)$ and were less frequently submitted to middle ear ventilation tube placement $(20 \%) .13$

Since October, 2000, Pnc7 vaccine has been part of the USA's routine vaccination calendar, being indicated for children from 2 to 60 months of age, administered intramuscularly, together with the other poliomyelitis, diphtheria, tetanus, pertussis, hepatitis $B$ and $H$. influenzae type b (IPV, DTP, HB, Hib) vaccines. The number of doses varies with the age at which the scheme is started (Table 3 ). ${ }^{12}$

\section{Impact of Pnc7 vaccine on IPD}

After the Pnc7 vaccine was implemented in the USA, a substantial reduction was found in the number of cases of invasive diseases in both vaccinated and non-vaccinated individuals. ${ }^{13-21}$

From 1998 to 2002 , the incidence rates of IPD in seven regions in the USA (16 million individuals) dropped from 24.3 cases per 100,000 to 17.3 per 100,000 . The greatest reduction in the incidence rates of IPD was observed in the age group of children under 2 years of age (69\%), and protection against IPD caused by VST was $78 \%$. Surprisingly, vaccination of children was associated with a drop of $35 \%$ in the incidence of IPD in people between the ages of 20 and 35 years, and $18 \%$ in people over the age of 65 years, and a reduction of $35 \%$ in the incidence of IPD caused by antibiotic resistant strains. ${ }^{14}$

In northern California, in 2003, the drop in IPD prevalence caused by pneumococcus strains fully resistant to penicillin was even greater $(15 \%$ in 2000 , to $5 \%$ in 2003). ${ }^{16}$

In September 2005, the Centers for Disease Control and Prevention (CDC) published the results of IPD surveillance in the USA. From 1998/1999 to 2003, the incidence of IPD by VST was reduced from 80 to 4.6 cases per 100,000 (94\%, 95\%CI 92-96\%), and the incidence of pneumoccocal diseases caused by any pneumococcal serotype (whether VST or not) was reduced by $75 \%$. According to the CDC, $69 \%$ of the impact of vaccination was related to the indirect effects of vaccination (herd immunity) and reduced colonization by pneumococcus of vaccinated children's respiratory tract, which resulted in reduced transmission of this bacteria to adults. Although a small increase occurred in the incidence of IPD by strains not included in the Pc7V vaccine, this increase was very 
Table 3 - Scheme for the use of conjugate Pnc7 vaccine

\begin{tabular}{|c|c|c|}
\hline First dose & Primary series & Additional doses \\
\hline 2-6 months & 3 doses $*$ & 1 dose, between 12 and 15 months $^{\dagger}$ \\
\hline 7-11 months & 2 doses $*$ & 1 dose, between 12 and 15 months ${ }^{\dagger}$ \\
\hline $12-23$ months & 2 doses $^{+}$ & - \\
\hline 2-5 years - healthy children in day care centers & 1 dose & - \\
\hline $2-5$ years - children at risk & 2 doses $^{\dagger}$ & \\
\hline
\end{tabular}

* In the first year of life, the minimum interval between the doses is 4 weeks.

$\dagger$ After 12 months and between additional doses, the minimum interval between doses is 2 months.

low, in comparison with the benefit obtained from vaccination. 17

Similar results were found in some provinces in Canada, where Pnc7 vaccine was introduced in the routine calendar as from September 2001. Active surveillance of IPD in these regions revealed that in children less than 2 years of age, the IPD rate fell from $82 / 100,000$ to $12 / 100,000$, without increase in infections by other serotypes. In the elderly ( $>65$ years), a drop in IPD of $63 \%$ was also recorded, probably as a result of collective immunity. ${ }^{18}$

\section{Impact of the vaccine in groups at high risk for IPD Preterm and low birth weight infants}

These children present higher risk for IPD when compared with full term children $(\mathrm{OR}=1.6$ and $\mathrm{OR}=2.6$, respectively). In a study that included 1,756 low birth weight children (LBWC) and 4,340 premature babies (32 to 38 weeks of gestation), the protection given by Pnc7 vaccine was $100 \%$ in preventing invasive diseases caused by VS in both groups. In comparison with children born at full term with adequate birth weight, the LBWC and premature babies presented more local adverse events (redness and edema), after the third dose of Pnc7 vaccine was applied, but the incidence of adverse systemic events was no different between the groups. ${ }^{19}$

\section{Blacks}

Before the introduction of Pnc7 vaccine in the USA, the IPD rates in African-Americans were 2.9 times higher in comparison with those found in other ethnic groups. Two years after the vaccine was introduced in the routine vaccination calendar, this difference fell to 2.2 even with only $68 \%$ vaccination cover. The impact of vaccination on African-American children $<5$ years old was $92 \%$, while in Caucasians the effectiveness was $87 \%$. In 1998/1999, the IPD rates registered in African-American and white children younger than 5 years were 180 and 58 per
100,000 , respectively; in 2002, these rates fell to 14.5 and 7.4 per 100,000 , below the target established by the Healthy People 2010 initiative (50/100,000 cases IPD for children under the age of 5 years). ${ }^{20}$

\section{Native Americans}

Native Americans also presented high incidence of IPD; in a controlled study that included 8,292 Navajo and Apache children, protection given by Pnc7 vaccine was $76.8 \%$, eight cases of IPD having been registered in the control group and two in the vaccinated group. ${ }^{21}$ In Alaska, the conjugate vaccine also showed excellent effectiveness. Although the highest impact was observed in native children, mass vaccination was also responsible for the significant reduction in IPD in non-natives and nonvaccinated adults. 22

\section{Impact of the vaccine on patients with chronic diseases}

There are still few data about the impact of Pnc7 vaccine in patients with chronic diseases. In a small randomized and controlled study conducted in the USA, in which children with and without HIV infection were compared, children with asymptomatic infection presented antibody response comparable to that of the non-infected, but due to the small number of children included, it was not possible to assess vaccination effectiveness. ${ }^{23}$ Based on the results of studies conducted with a new 9-valent (Pnc9) conjugate vaccine, formulated with the same protein as the Pnc7 vaccine (CRM 197), which also contains ST 1 and 5, it is possible, however, to predict that the protection given by conjugate vaccines in HIV infected children should be substantial.24,25 In Soweto (South Africa), a region with high prevalence of HIV infection, a controlled study was conducted in which 19,914 children were vaccinated with Pnc9 vaccine and 19,914 received placebo. The protection given to HIV infected children was $65 \%$, while in the non-infected children it was $83 \%$. The 
incidence of pneumonia confirmed by chest X-ray exam was reduced by $20 \%$ in vaccinated children; diseases caused by pneumococcus strains resistant to penicillin and sulfamethoxazole trimethoprim were reduced by 67 and $56 \%$, respectively. ${ }^{24}$ Another study conducted with Pnc9 vaccine was carried out in Gambia (Africa), and showed a significant reduction in the number of pneumonias and deaths (seven deaths prevented for every 1,000 children immunized). ${ }^{25}$ Recently, results of active surveillance on IPD in an area of the USA in which there are over 10 million adults (18 to 64 years), among whom 38,314 with AIDS, were published. In this region, after the Pnc7 vaccine was implemented in the children's calendar, a reduction in the IPD rates in adults with AIDS was found, from 1,127 in $1998 / 1999$, to 919 per 100,000 in 2004. In spite of there being an increase of $44 \%$ in the detection of ST not included in Pnc7 vaccine, the reduction in the incidence of IPD in this group was $19 \%$, with a drop of $62 \%$ in the DPI due to TS included in the vaccine. These alterations were attributed to herd immunity. 26

\section{Reduction of morbidity in persons with viral infections}

Persons with viral infections are at high risk of presenting with bacterial complications, such as otitis, sinusitis or pneumonia from pneumococcus. ${ }^{27-29}$ In the USA, it was found that after the Pnc7 vaccine was implemented in the routine calendar, there was substantial reduction in the cases of IPD and influenza-like diseases, both in vaccinated children and in adults and the elderly. In this study, it was not possible to know whether the viral infections were milder in the years following vaccination, and for this reason there was lower incidence of IPD, or whether vaccination contributed to the reduction in the respiratory diseases diagnosed as probably having viral etiology. ${ }^{29}$ In another study conducted in Africa, however, Pnc9 reduced the diagnoses of pneumonias that were proved to have been caused by virus by $31 \%$, confirming the literature data that superinfection by pneumococcus is very common after viral infections, particularly by influenza virus and respiratory syncytial virus. ${ }^{27}$

\section{Impact of Pnc7 vaccine on respiratory tract colonization by $S$. pneumoniae}

Respiratory tract colonization by $S$. pneumoniae precedes the occurrence of invasive and non-invasive diseases. 30 The prevalence of healthy pneumococcus carriers is higher in children, particularly in those who attend day care centers, and in adults in contact with children. In Brazil, several studies have shown a colonization rate of about $40 \%$ in children less than 2 years of age. ${ }^{31-34}$

Conjugate vaccines reduce the pneumococcus colonization rates and consequently the transmission of these bacteria in the community, thus playing a relevant role in herd immunity. This is important, although there is not always correlation between the serotypes that colonize the respiratory tract and those isolated in persons with invasive diseases. Serotypes 1 and 5 are frequently isolated in persons with IPD, but rarely isolated in the nasopharynx of healthy carriers. Serotypes $14,6 \mathrm{~B}$ and $23 \mathrm{~F}$, however, are frequently isolated in persons wit IPD and healthy carriers. 33

Several other studies reveal that conjugate pneumococcus vaccine administered to children is capable of inducing collective immunity, and most probably the protection of non-vaccinated persons is due to the reduction in respiratory tract colonization. $16-18,20,22$ The majority of the $S$. pneumoniae serotypes resistant to penicillin and to other antibiotics are represented in the Pnc7 vaccine; as the vaccine reduces respiratory tract colonization rates and transmission of these serotypes in the community, the vaccination of children indirectly reduces the rate of colonization by resistant strains in non-vaccinated persons, with a drop in the IPD caused by resistant strains in children and adults. ${ }^{5-10,16-18,31-36}$

Studies conducted in Israel confirmed that the use of conjugate vaccines is associated with the reduction of the VST carriers' status and of strains resistant to one or more antibiotics. ${ }^{35-37}$ In addition, the vaccinated group received fewer antibiotics than the control group (17\% fewer days of antibiotics). ${ }^{35}$ The rates of colonization by VST were inversely related to the IgG class antibody concentrations, indicating that collective immunity must be related to the magnitude of the response. ${ }^{37}$ As vaccination of children older than 1 year induces more antibody titres against all the VSTs, it is believed that a conjugate vaccine booster dose plays a relevant role in inducing collective immunity. 1,16

\section{Impact of Pnc7 vaccine on pneumonias}

The result of studies that assessed the impact of conjugate vaccine use in respiratory diseases, particularly in more serious lower airway infections, such as pneumonias, are of great relevance to Brazil, bearing in mind that pneumococcus is the main etiologic agent of these infections. Figure 1 shows the results of studies which assessed the impact of conjugate pneumococcus serotypes (PS) and VST vaccines. ${ }^{16,21,24,25}$ In a study conducted in the USA (Kaiser Permanent), the protection given against pneumonia with radiological confirmation was higher than 59\%, and for clinically diagnosed pneumonias (without radiological confirmation), 11\%. ${ }^{16}$

It is important to emphasize that clinical and radiological definition of pneumonia is very difficult. ${ }^{4}$ Nonetheless, a large part of the pneumococcus isolates in Brazil come from pulmonary infections. ${ }^{38-40}$ Contrary to the findings in the USA, in which the majority of the pneumococcus strains are isolated in patients with bacteremia, in studies 


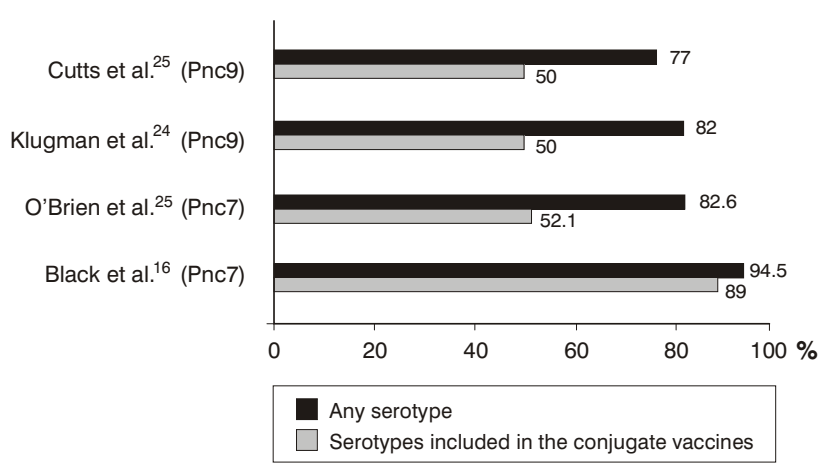

Figure 1 - Conjugate pneumococcal vaccine efficacy against pneumonias $16,21,24,25$ in accordance with the serotypes (\%)

coming from Latin America, around 50\% of the pneumococci are isolated from persons with pneumonia. Recent data from a collaborative pneumonia surveillance study in Latin America (Caribbean Project) projected a potential protection of around $60 \%$ with the conjugate pneumonia vaccine. 41

It is important to draw attention to the studies conducted in Africa demonstrating the effectiveness of conjugate pneumonia vaccine. 24,25 The Gambia study was randomized, with double-blind control and involved 22,000 children. The protection given by Pnc9 vaccine for radiologically confirmed pneumonia was $27 \%$, and in comparison with the control group, there were $16 \%$ fewer deaths in vaccinated children. 25

\section{Impact of Pnc7 vaccine on replacement by non- vaccination serotypes and other bacteria}

Several studies indicate that in vaccinated children, the VSTs that colonize the respiratory tracts are replaced with PS not included in the vaccine, or by other bacteria, such as non-typeable $H$. influenzae. $17,18,26,36,37,42-44$ Although this phenomenon has been evidenced in several studies, the benefits of the use of conjugate vaccines are greater than the risk of infections by PS not included in the vaccine or by other less pathogenic bacteria and with less resistance to antibiotics. The increased prevalence of $H$. influenzae strains, producers of beta-lactamases in the airways of vaccinated children is of concern; while some studies indicate that the use of conjugate vaccines reduces the number of AOM episodes, others indicate there could even be an increase in the number of otitis cases, but with less severity in comparison with those caused by $S$. pneumoniae. All the data, however, present a reduction in the rate of severe forms of AOM in the vaccinated population. ${ }^{35-37}$ The appearance of serotype $19 \mathrm{~A}$, which over the last 5 years grew in importance among invasive and non-invasive diseases, is an exception to this rule. ${ }^{43,44}$

Of all the ST included in Pnc7 vaccine, the ST 19F is the one that induces least response. At present, it is known that this vaccine does not give cross-protection against ST 19A. ${ }^{37}$ The inappropriate use of antibiotics to treat acute respiratory infections is the main factor associated with increased bacterial resistance. 5,6 As conjugate vaccine does not give protection against ST 19 A, which frequently colonizes children's respiratory tracts, the use of conjugate vaccines alone is not sufficient to control the problem of resistance in the community. Furthermore, we emphasize that in spite of new pneumococcus STs having been identified as IPD agents in the USA, vaccination had enormous impact on both the vaccinated and nonvaccinated and the indirect effects were responsible for approximately $2 / 3$ of the benefits of the vaccine. Thus, it is fundamental to reassess the benefits and costs of vaccination, taking collective immunity into account. $18,44-50$

\section{Status of IPD in Brazil and the potential impact of Pnc7 vaccine}

In Brazil, after the introduction of Hib vaccine, $S$. pneumoniae is the second agent most frequently isolated from bacterial meningitis cases. The rate of incidence of meningitis from pneumococcus in the Brazilian population is around 1 to 1.5 per 100,000 inhabitants. ${ }^{11}$ In children under the age of 5 years, the lethality of meningitis from S. pneumoniae is higher than $30 \%$. In the state of São Paulo, over 500 cases of meningitis are recorded every year, $38-40$ and the coefficients of incidence in children under the age of 5 years are higher in comparison with the population, reaching 17 per 100,000 in children under the age of 2 years (Table 4 ). ${ }^{41}$ In a study with follow-up of 55 children hospitalized in a tertiary hospital in São Paulo, the mortality rate found was $20 \% ; 40 \%$ had neurological sequelae and $60 \%$ hearing loss after meningitis from $S$. pneumoniae, proving the high morbidity of pneumococcal meningitis. ${ }^{7}$

IPD surveillance is coordinated by the Adolfo Lutz Institute in São Paulo. Analysis of over 6,000 pneumococcus strains isolated over the last few years revealed that as from 2000, the prevalence of strains resistant to penicillin increased drastically, reaching $30 \%$ in 2004 . Isolation of strains fully resistant to penicillin $(\geq 2,0 \mu \mathrm{g} / \mathrm{mL}$ ) grew more than five times over the last 5 years, and since 2003, is higher than $6 \%$, exceeding that found in the USA after Pnc7 vaccine implementation. ${ }^{38-40}$

All over the world, the PS most resistant to antibiotics are $14,6 \mathrm{~B} / 6 \mathrm{~A}, 23 \mathrm{~F}, 19 \mathrm{~A} / 19 \mathrm{~F}$ and $9 \mathrm{~V} \cdot 1-3,6-10,31-36$ In Brazil, ST 14 is the most associated with resistance to penicillin and other antibiotics (56\% resistance, 25\% being fully resistant to penicillin). Pnc7 vaccine contemplates approximately $70 \%$ of the ST isolated from Brazilian children with IPD diagnosed in the age group from 7 to 24 months; $60 \%$ of the ST identified in cases of meningitis diagnosed in children between the ages of 2 and 5 years; and $40 \%$ of the ST isolated from children in 
this age group diagnosed as having pneumonia with bacteremia and/or pleural effusion. In addition to this, it should be pointed out that over $95 \%$ of the strains resistant to penicillin are represented in this vaccine. ${ }^{28-40}$ Therefore, it is expected that Pnc7 vaccine implementation could reduce not only the incidence of IPD, but also the dissemination of resistant strains (mainly ST14).

The increased prevalence of pneumococcus strains resistant to penicillin found in Brazil was associated with the increased frequency of ST 14 and reduction in isolation of ST 1 which, as is the case with ST 3 and 5, is frequently isolated from children with IPD, but is rarely isolated from healthy carriers. For this reason, ST 1, 3 and 5 are less exposed and present lower resistance to antibiotics, while ST 19A is frequently isolated from IPD and also from healthy child carriers, thus being more likely to develop resistance to antimicrobial agents. ${ }^{31-37}$ Analyzing the variations in the prevalence of various pneumococcus ST, and also the resistance rates, requires a great deal of caution, as there are wide variations in the prevalence of the various ST and in bacterial resistance, in accordance with the region, age group, time of the year and period of isolation of the strains. It should be emphasized that pneumococcus and other bacteria that colonize the respiratory tract frequently undergo genetic alterations, and may acquire resistance genes from other STs. While few $S$. pneumoniae clones were identified at the beginning of the 1990s in Brazil, at present the genotypic variation is much greater, and it is essential to maintain epidemiological surveillance on the most prevalent STs in the various age groups. 8,9

As the STs most frequently isolated from children with invasive and non-invasive diseases are the ones that present the greatest clonal variation, it is essential to develop new vaccines for preventing pneumococcal diseases. ${ }^{8,9}$ At present, ST $19 \mathrm{~A}$ is the one that causes the greatest concern, not only because of being frequently isolated from vaccinated children that present with IPD in the USA, but also due to the increase in the rate of resistance to antimicrobial agents. ${ }^{8,9,43,44}$ Inclusion of a larger number of serotypes in conjugate vaccines, particularly of those that most cause IPD and are most associated with bacterial resistance, such as $1,3,5,6 \mathrm{~B}$, $19 A$, would be very welcome. The new conjugate vaccines have, however, not yet been licensed, as it is necessary to assess the risks, benefits and implementation costs of conjugate Pnc7 vaccine for children at risk and previously healthy children. The economic impact of pneumococcal diseases in previously healthy children is hardly studied in Brazil. For this reason, the Pnc7 vaccine is offered in the public health service only to children at high risk of developing invasive diseases, such as patients with severe cardio-respiratory disease, congenital, or acquired immunodeficiency or asplenia; however, the majority of deaths, hospitalizations and sequelae from IPD occur in previously healthy children. We emphasize that children under the age of 5 years, those with siblings under the age of 5 years, children that attend day care centers or live in crowded environments, polluted by cigarette smoke and asthmatic children also present higher risk for developing IPD. $1,4,6,10,12-25,27-30$

\section{Cost-effectiveness of Pnc7 vaccine}

At present, the best parameter for analyzing the costs of diseases are disability-adjusted life years (DALYs). This index measures the number of years lost due to death and disability. Thus, considering a normal life as 1.0, a child with pneumococcal meningitis and neurological sequelae, would present a loss of 0.76 DALY units. ${ }^{45}$ In the USA, in the pre-conjugate vaccine era, it was estimated that for a cohort of 3.8 million children, Pnc7 vaccine could prevent 12,000 cases of meningitis and bacteremia (78\%), 53,000 cases of pneumonia (69\%) and 1 million cases of AOM $(8 \%)$. The reduction in spending on disease would reach 342 million dollars in medical costs and 415 million dollars in social costs (loss of work and others). From the social point of view, vaccination would be cost-effective at a cost lower than 46 dollars per dose and for the health service, at a cost lower than 18 dollars per dose. ${ }^{45}$ In this study, the indirect benefits of vaccination, which apparently were responsible for $2 / 3$ of the drop in the incidence of IPD in the USA, were not taken into account and nor was the

Table 4 - Coefficients of incidence and mortality of pneumococcal meningitis by age group (state of São Paulo, 2004)

\begin{tabular}{ccccc}
\hline Age group (years) & Coefficient/100,000 & Cases (no.) & Deaths (no.) & Mortality (\%) \\
\hline$<1$ & 17.4 & 116 & 37 & 31.9 \\
$1-4$ & 2.4 & 65 & 23 & 35.4 \\
$5-9$ & 1.3 & 45 & 8 & 17.8 \\
$10-14$ & 0.1 & 20 & 5 & 25.0 \\
$15-19$ & 0.7 & 27 & 3 & 11.1 \\
$20-29$ & 0.7 & 100 & 18 & 18.0 \\
$\geq 40$ & 1.1 & 129 & 49 & 38.0 \\
Total & 1.3 & 502 & 143 & 28.5 \\
\hline
\end{tabular}

Source: CVE. Data up to November 22, 2005 (http://www.cve.saude.sp.gov.br). 
impact of vaccination on the reduction of diseases caused by strains resistant to antibiotics. ${ }^{16,39}$ More recent studies conducted in Australia, France, Canada, Germany and the United Kingdom revealed that the cost-benefit ratio of large scale vaccination is much higher, taking into account the impact on non-vaccinated persons. ${ }^{46-49}$

In Australia, a variation in the rate of pneumococcal disease of 297 to $2,000 / 100,000$ children under the age of 2 years was observed, depending on the population analyzed; the cost per year of life saved with the use of Pnc7 vaccine was calculated to be 190,000 Australian dollars, and by DALY, 104,000 Australian dollars. ${ }^{46}$ In comparison with other regions of the world, however, the mortality rate from pneumococcal disease is low in Australia. 47

In a study conducted in Gambia (Africa), the calculation was that for 1,000 children vaccinated, one life was saved. In this scenario, the cost-effectiveness analysis of the vaccine would be even more favorable. ${ }^{25}$

Taking into account that the majority of French children under the age of 5 years present at least one additional factor for IPD (prematurity, low birth weight, breastfeeding for a period shorter than 2 months, attending day care centers, precarious social conditions), Pnc7 vaccine was implemented in the routine calendar of France. ${ }^{47}$ the same occurred in other countries, such as Canada, Australia and the United Kingdom. The conjugate vaccine is recommended by various medical societies in different countries, including the Brazilian Society of Pediatrics.

In Brazil, before Pnc7 vaccine is included in the Brazilian vaccination calendar, it is foreseen that costeffectiveness studies will be made, but the difficulty in confirming the etiology of pneumonias, which constitute the largest source of hospital spending on infectious diseases, needs to be considered. In 2004, public spending on children under the age of 5 years, hospitalized in the public health services due to pneumonia was 180 million dollars. Estimating that $1 / 3$ of these pneumonias were caused by pneumococcus, every year 90 million dollars would be spent only on the treatment of children hospitalized because of pneumococcal pneumonia. ${ }^{11}$ Compared with public spending to treat pneumococcal meningitis, estimated at 11.8 million per annum, spending on the treatment of pneumonia is much higher. ${ }^{45-49}$

\section{Final considerations}

Although the cost of conjugate vaccine is still very high, in comparison with other vaccines, it should be considered that pneumonia kills many children and that meningitis from pneumococcus and other IPDs is responsible for a large number of deaths and sequelae in children. Children of low-income families are the most vulnerable to IPDs and are the ones that are in the least position to receive the vaccine. ${ }^{1,4}$ Furthermore, the effectiveness of conjugate vaccine in some risk groups, such as HIV patients, is low, 23,50,51 a large part of the IPDs occur in LBWC or premature babies or those under the age of 6 months. ${ }^{19,20}$ These groups would certainly benefit from the inclusion of Pnc7 vaccine in the routine calendar, as recommended by the Brazilian Society of Pediatrics. Furthermore, an even greater impact may be expected on the reduction of hospitalizations and deaths by IPD in adults. Thus, we believe that pediatricians should recommend Pnc7 vaccine for every previously healthy child between the ages of 2 and 60 months. It should be emphasized that, in Brazil, both conjugate and polysaccharide pneumococcal vaccines are available free of charge at the Special Immunobiology Referral Centers (CRIE - Centros de Referência para Imunobiológicos Especiais) for children with immunodeficiency, asplenia and severe cardio-pulmonary diseases. These groups must receive the polysaccharide vaccine after they reach the age of 2 years.

\section{Conflict of interest}

Lucia Ferro Bricks declares that she has delivered lectures on vaccines on behalf of the Merck Sharp \& Dohme, Sanofi-Pasteur and Wyeth laboratories. She has also participated in research projects and medical congresses sponsored by these laboratories. She is currently one of the investigators working on an international multicenter study into interference between oral rotavirus (MSD pentavalent) and poliomyelitis vaccines, sponsored by the Merck Sharp \& Dohme Laboratory. Eitan Berezin declares that he lectures for the Wyeth Laboratory and carries out research for them.

\section{References}

1. Fedson DS, Musher DM. Pneumococcal polysaccharide vaccine. In: Plotkin SA Orestein WA Vaccines, 4th ed. Philadelphia: WB Saunders; 2004. p. 529-88.

2. World Health Organization. Working Group for economic evaluation of pneumococcal and Haemophilus influenzae type b vaccines: report of the first meeting. Geneva: WHO; 2000.

3. Rudan I, Tomaskovic L, Boschi-Pinto C, Campbell H, WHO Child Health Epidemiology Reference Group. Global estimate of the incidence of clinical pneumonia among children under five years of age. Bull WHO 2004:82:895-903.

4. Andrade AL, Silva SA, Martelli CM, Oliveira RM, Morais Neto OL, Siqueira Junior JB, et al. Population-based surveillance of pediatric pneumonia: use of spatial analysis in an urban area of Central Brazil. Cad Saude Publica. 2004;20:411-21.

5. Amsden GW. Pneumococcal resistance in perspective: how well are we combating it? Pediatr Infect Dis J. 2004;23(2 Suppl): S125-8.

6. Bricks LF, Berezin EN, Silveira L. Uso de antibióticos em IRA e resistência bacteriana. In: Bricks LF, Cervi MC, organizadoras. Atualidades em doenças infecciosas: manejo e prevenção. São Paulo: Atheneu; 2002. p. 197-214.

7. Berezin EN, Carvalho LH, Lopes CR, Sanajotta AT, Brandileone MC Menegatti S, et al. Meningite pneumocócica em crianças: achados clínicos, sorotipos mais freqüentes e prognóstico. J Pediatr (Rio J). $2002 ; 78: 19-23$.

8. Mantese OC, Paula A, Moraes AB, Moreira TA, Guerra ML, Brandileone MC. Prevalência de sorotipos e resistência bacteriana de cepas invasivas do Streptococcus pneumoniae. J Pediatr (Rio J). 2003;79:537-42.

9. Zemlickova H, Crisostomo MI, Brandileone MC, Camou T, Castaneda E, Corso A, et al. Serotypes and clonal types of penicillin-susceptible Streptococcus pneumoniae causing invasive disease in children in five Latin American countries. Microb Drug Resist. 2005;11:195-204. 
10. Arguedas A, Dagan R, Guevara S, Porat N, Soley C, Perez A, et al. Middle ear fluid Streptococcus pneumoniae serotype distribution in Costa Rican children with otitis media. Pediatr Infect Dis J. 2005;24:631-4.

11. Brasil, Ministério da Saúde. Data-Sus Brasil. http://www.saude. gov.br. Access: 08/12/2005.

12. Black S, Shinefield H, Fireman B, Lewis E, Ray P, Hansen JR, et al. Efficacy, safety and immunogenicity of heptavalent pneumococcal conjugate vaccine in children. Northern California Kaiser Permanente Vaccine Study Center Group. Pediatr Infect Dis J. 2000;19:187-95.

13. Black SB, Shinefield HR, Hansen J, Elvin L, Laufer D, Malinoski F. Postlicensure evaluation of the effectiveness of seven valent pneumococcal conjugate vaccine. Pediatr Infect Dis J. 2001;20: $1105-7$.

14. Whitney CG, Farley MM, Hadler ], Harrison LH, Bennett NM, Lynfield $R$, et al. Decline in invasive pneumococcal disease after the introduction of protein-polysaccharide conjugate vaccine. $N$ Engl J Med. 2003;348:1737-46.

15. Poehling KA, Lafleur BJ, Szilagyi PG, Edwards KM, Mitchel E, Barth $R$, et al. Population-based impact of pneumococcal conjugate vaccine in young children. Pediatrics. 2004;114: 755-61.

16. Black $S$, Shinefield $H$, Baxter $R$, Austrian R, Bracken $L$, Hansen J, et al. Postlicensure surveillance for pneumococcal invasive disease after use of heptavalent pneumococcal conjugate vaccine in Northern California Kaiser Permanente. Pediatr Infect Dis J. 2004;23:485-9.

17. Centers for Disease Control and Prevention (CDC). Direct and indirect effects of routine vaccination of children with 7-valent pneumococcal conjugate vaccine on incidence of invasive pneumococcal disease - United States, 1998-2003. MMWR Morb Mortal Wkly Rep. 2005;54:893-7.

18. Kellner JD, Church DL, MacDonald J, Tyrrell GJ, Scheifele D. Progress in the prevention of pneumococcal infection. CMAJ. 2005; 173:1149-51.

19. Shinefield H, Black S, Ray P, Fireman B, Schwalbe J, Lewis E. Efficacy, immunogenicity and safety of heptavalent pneumococcal conjugate vaccine in low birth weight and preterm infants. Pediatr Infect Dis J. 2002;21:182-6.

20. Flannery B, Schrag S, Bennett NM, Lynfield R, Harrison LH, Reingold $A$, et al. Impact of childhood vaccination on racial disparities in invasive Streptococcus pneumoniae infections. JAMA. 2004;291:2197-203.

21. O'Brien KL, Moulton LH, Reid R, Weatherholtz R, Oski J, Brown L, et al. Efficacy and safety of seven-valent conjugate pneumococcal vaccine in American Indian children: group randomized trial. Lancet. 2003;362:355-61.

22. Hennessy TW, Singleton RJ, Bulkow LR, Bruden DL, Hurlburt DA, Parks $D$, et al. Impact of heptavalent pneumococcal conjugate vaccine on invasive disease, antimicrobial resistance and colonization in Alaska Natives: progress towards elimination of a health disparity. Vaccine. $2005 ; 23: 5464-73$.

23. Nachman S, Kim S, King J, Abrams EJ, Margolis D, Petru A, et al. Safety and immunogenicity of a heptavalent pneumococcal conjugate vaccine in infants with human immunodeficiency virus type 1 infection. Pediatrics. 2003;112:66-73.

24. Klugman KP, Madhi SA, Huebner RE, Kohberger R, Mbelle N, Pierce $\mathrm{N}$, et al. A trial of a 9 -valent pneumococcal conjugate vaccine in children with and those without HIV infection. $\mathrm{N}$ Engl J Med. 2003;349:1341-8.

25. Cutts FT, Zaman SM, Enwere G, Jaffar S, Levine OS, Okoko JB, et al. Efficacy of nine-valent pneumococcal conjugate vaccine against pneumonia and invasive pneumococcal disease in the Gambia: randomized, double-blind, placebo-controlled trial. Lancet. 2005;365:1139-46.

26. Flannery B, Heffernan RT, Harrison LH, Ray SM, Reingold AL, Hadler $\mathrm{J}$, et al. Changes in invasive pneumococcal disease among HIVinfected adults living in the era of childhood pneumococcal immunization. Ann Intern Med. 2006;144:1-9.

27. Madhi SA, Klugman KP; Vaccine Trialist Group. A role for Streptococcus pneumoniae in virus-associated pneumonia. Nat Med. 2004;10:811-3.

28. Gutierrez F, Masia M, Rodriguez JC, Mirete C, Soldan B, Padilla S. Community-acquired pneumonia of mixed etiology: prevalence, clinical characteristics, and outcome. Eur J Clin Microbiol Infect Dis. 2005;24:377-83.

29. Shafinoori S, Ginocchio CC, Greenberg AJ, Yeoman E, Cheddie M, Rubin LG. Impact of pneumococcal conjugate vaccine and the severity of winter influenza-like illnesses on invasive pneumococcal infections in children and adults. Pediatr Infect Dis J. 2005;24:10-6.

30. Bogaer D, Groot R, Hermans PW. Streptococcus pneumoniae colonization: the key to pneumococcal disease. Lancet Infect Dis. 2004; $4: 144-54$

31. Lucarevschi BR, Baldacci ER, Bricks LF, Bertoli CJ, Teixeira LM, Mendes CMF, et al. Colonização da orofaringe de crianças por Streptococcus pneumoniae em crianças de creches de Taubaté (SP): correlação entre os principais sorotipos e a vacina conjugada heptavalente. J Pediatr (Rio J). 2003;79:215-20.
32. Ferreira LLM, Carvalho ES, Berezin EN, Brandileone MC. Colonização e resistência antimicrobiana e Streptococcus pneumoniae isolado em nasofaringe de crianças com rinofaringite aguda. J Pediatr (Rio J). $2001 ; 77: 227-34$.

33. Rey LC, Wolf B, Moreira JLB, Verhoef J, Farhat CK. S. pneumoniae isolados da nasofaringe de crianças sadias e com pneumonia: taxa de colonização e susceptibilidade aos antimicrobianos ] Pediatr (Rio J). $2002 ; 78: 105-12$.

34. Berezin EN, Cardenuto MD, Otsuka M, Ferreira LL, Guerra ML, Brandileone MC, et al. Avaliação do uso de isolados de S. pneumoniae de swab de nasofaringe para avaliar resistência bacteriana em crianças de S. Paulo. Rev Paul Pediatr. 2003:21: 179-85.

35. Dagan R, Sikuler-Cohen M, Zamir O, Janco J, Givon-Lavi N, Fraser $D$. Effect of a conjugate pneumococcal vaccine on the occurrence of respiratory infections and antibiotic use in day-care center attendees. Pediatr Infect Dis J. 2001;20:951-8.

36. Dagan R, Givon-Lavi N, Zamir O, Sikuler-Cohen M, Guy L, Janco J, et al. Reduction of nasopharyngeal carriage of Streptococcus pneumoniae after administration of a 9-valent pneumococcal conjugate vaccine to toddlers attending day care centers. J Infect Dis. 2002; 185:927-36.

37. Dagan R, Givon-Lavi N, Fraser D, Lipsitch M, Siber GR, Kohberger R. Serum serotype-specific pneumococcal anticapsular immunoglobulin $\mathrm{G}$ concentrations after immunization with a 9valent conjugate pneumococcal vaccine correlate with nasopharyngeal acquisition of pneumococcus. J Infect Dis. 2005;192:367-76.

38. Brandileone MC, de Andrade AL, Di Fabio JL, Guerra ML, Austrian R. Appropriateness of a pneumococcal conjugate vaccine in Brazil: potential impact of age and clinical diagnosis, with emphasis on meningitis. J Infect Dis. 2003;187:1206-12.

39. Carvalhanas TR, Brandileone MC, Zanella RC. Meningites bacterianas. Boletim Epidemiológico Paulista (BEPA). 2005;17. http:// www.cve.saude.sp.gov.br. Access: 08/12/2005.

40. Centro de Vigilância Epidemiológica Prof. Alexandre Vranjac. http:/ /www.cve.saude.sp.gov.br. Access: 08/12/2005.

41. Ruvinsky R, Berezin EN, Ferrero F, Feris J, Brandileone MC, Maggi RS, et al. Latin American multicentre study on pneumonia in young children: pneumococcal serogroups and penicillin resistance. Intern J Infect Dis. 2004;8:S63.

42. Block SL, Hedrick J, Harrison CJ, Tyler R, Smith A, Findlay R, et al. Community-wide vaccination with the heptavalent pneumococcal conjugate significantly alters the microbiology of acute otitis media. Pediatr Infect Dis J. 2004;23:829-33.

43. Porat N, Arguedas A, Spratt BG, Trefler R, Brilla E, Loaiza C, et al. Emergence of penicillin-nonsusceptible Streptococcus pneumoniae clones expressing serotypes not present in the antipneumococcal conjugate vaccine. J Infect Dis. 2004;190: 2154-61.

44. Pai R, Moore MR, Pilishvili T, Gertz RE, Whitney CG, Beall B, et al. Postvaccine genetic structure of Streptococcus pneumoniae serotype 19A from children in the United States. J Infect Dis. 2005;192: 1988-95.

45. Black S, Lieu TA, Ray GT, Capra A, Shinefield HR. Assessing costs and cost effectiveness of pneumococcal disease and vaccination within Kaiser Permanente. Vaccine. 2000;19 Suppl 1:S83-6.

46. Butler JR, McIntyre P, MacIntyre R, Gilmour R, Howarth AL, Sander $B$. The cost effectiveness of pneumococcal conjugate vaccination in Australia. Vaccine. 2004;22:1138-49.

47. Calendrier vaccinal 2005 et autres avis du Conseil supérieur d'hygiène publique de France relatifs à la vaccination. Bulletin Épidémiologique Hebdomadaire (BEH). 2005;29-30.

48. Lebel MH, Kellner JD, Ford-Jones EL, Hvidsten K, Wang EC, Ciuryla $\mathrm{V}$, et al. A pharmacoeconomic evaluation of 7-valent pneumococcal conjugate vaccine in Canada. Clin Infect Dis. 2003;36:259-68.

49. McIntosh ED, Conway P, Willingham J, Lloyd A. The cost-burden of paediatric pneumococcal disease in the UK and the potential costeffectiveness of prevention using 7-valent pneumococcal conjugate vaccine. Vaccine. 2003;21:2564-72.

50. Tarrago D, Casal J, Ruiz-Contreras J, Ramos JT, Rojo P, Snippe H, et al. Assessment of antibody response elicited by a 7-valent pneumococcal conjugate vaccine in pediatric human immunodeficiency virus infection. Clin Diagn Lab Immunol. 2005; $12: 165-70$.

51. Madhi SA, Kuwanda L, Cutland C, Holm A, Kayhty H, Klugman KP. Quantitative and qualitative antibody response to pneumococcal conjugate vaccine among African human immunodeficiency virusinfected and uninfected children. Pediatr Infect Dis J. 2005;24: 410-6.

\section{Correspondence:}

Lucia Ferro Bricks

Av. Dr. Eneas de Carvalho Aguiar, 647

CEP 05403-900 - São Paulo, SP - Brazil

Tel.: +55 (11) 3069.8738 - Fax: +55 (11) 3069.8503

E-mail: Ifbricks@gmail.com 